\title{
Effect of coercion, perceived coercion and treatment on criminal justice and psychiatric outcomes Nahama Broner ${ }^{1,2}$
}

\author{
Address: ${ }^{1}$ Research Triangle Institute (RTI) International, 113 University Place, Suite 1009, New York, NY 10003, USA and ${ }^{2}$ New York University, \\ 113 University Place, New York, NY 10003, USA \\ from WPA Thematic Conference. Coercive Treatment in Psychiatry: A Comprehensive Review \\ Dresden, Germany. 6-8 June 2007 \\ Published: 19 December 2007
}

BMC Psychiatry 2007, 7(SuppI I):S37 doi:I0.II86/I47I-244X-7-SI-S37

This abstract is available from: http://www.biomedcentral.com/I47I-244X/7/SI/S37

C 2007 Broner; licensee BioMed Central Ltd.

\section{Background}

Individual studies have demonstrated effects for pre-and post-booking diversion; multi-site studies have more modest findings and little is known about the comparative effects of different models in terms degree of coercion. To disaggregate the general effects of diversion, main effects and interaction effects of coercive strategies and perceived coercion.

\section{Methods}

A comparison study of 174 jail detainees with co-occurring serious mental and addictive disorders assessed on psychosocial, mental health, substance abuse, criminal justice, and satisfaction domains at baseline, 3 and 12months through self-report standardized instruments and services data, and collateral criminal justice data one-year prior and one-year following division. Matched participants were in one of three conditions: diversion eligible but not recruited to a diversion program, diverted through court programs that mandated conditions through deferred sentencing, and diverted through general diversion without follow-up criminal justice sanctions for noncompliance with legal conditions.

\section{Results}

Mandated diversion clients were less likely to spend as much time in prison, more likely to spend time in the community, more likely to have been linked to residential and outpatient treatment and other services, to have received more treatment, to experience decreased symptoms if non-medication compliant and to decrease drug use. Those who did not perceive themselves coerced and had insight into their mental illness received more treatment regardless of diversion condition. Treatment and the structure of that treatment regardless of condition predicted decrease in jail and prison days, and re-arrests.

\section{Conclusion}

While mandated diversion was found effective for some outcomes, less coercive strategies, individual characteristics and treatment significantly contributed. 